\title{
Análise dos efeitos dos tratamentos térmicos de solubilização e envelhecimento artificial sobre a microestrutura da liga de alumínio A356
}

\author{
Analysis of the effects of solution heat \\ treatment and artificial aging on the \\ microstructure of aluminum \\ alloy A356
}

Elisa Hellen Segundo ${ }^{1}$, Guilherme Ourique Verran², Girrese de Matos Batista ${ }^{3}$

\author{
${ }^{1}$ Laboratório de Fundição - DEM/PGCEM/CCT/UUDESC, Joinville, SC, Brasil \\ e-mail: lee.segundo@gmail.com \\ 2,3 Laboratório de Fundição - DEM/PGCEM/CCT/UUDESC, Joinville, SC, Brasil \\ 2e-mail: guilherme.verran@udesc.br \\ 3e-mail: girresemb@gmail.com
}

\begin{abstract}
RESUMO
Neste trabalho, foram investigados os efeitos dos tratamentos térmicos de solubilização e envelhecimento artificial (T6) sobre a microestrutura da liga 356 (Al7Si0,3Mg). Para a caracterização dos resultados, foram utilizados ensaios de microdureza e técnicas de microscopia ótica e eletrônica. Amostras fundidas da liga A356 com diferentes percentuais em peso de $\mathrm{Mg}$ (0,28\%, 0,38\% e 1\%) foram solubilizadas durante $10 \mathrm{~h}$ a $540^{\circ} \mathrm{C}$ e submetidas a diferentes tempos e temperaturas de envelhecimento artificial. Os resultados mostraram que a dureza aumenta com o aumento de temperatura de envelhecimento, mas apresenta uma queda brusca em amostras expostas a temperaturas mais elevadas $\left(215^{\circ} \mathrm{C}\right)$. Quanto ao tempo de envelhecimento, foram observados incrementos nos valores de dureza para o uso de maiores tempos. Com o intuito de identificar as alterações microestruturais associadas com estas variações nas propriedades mecânicas, bem como identificar os mecanismos envolvidos, foram realizadas análises via microscopia óptica, microscopia eletrônica de varredura e de transmissão. Constatou-se, em função das adições crescentes de magnésio, alterações significativas na microestrutura e no endurecimento da matriz da liga A356. No entanto, os fenômenos microestruturais associados ao endurecimento por precipitação somente foram detectados usando microscopia eletrônica de transmissão, que revelou a presença dos nano precipitados responsáveis pelo endurecimento por precipitação bem como dos precipitados incoerentes com a matriz que indicam a ocorrência de superenvelhecimento.
\end{abstract}

Palavras-chave: tratamentos térmicos, ligas de alumínio, endurecimento por precipitação, microscopia eletrônica de transmissão.

\section{ABSTRACT}

The present study investigated the effects of solution heat treatment and artificial aging (T6) on the microstructure of the A356 (Al7Si0.3Mg) aluminum alloy. To characterize the results, micro hardness test and techniques of light and electron microscopy were used. Samples of the A356 alloy casting, with distinct weight percent of $\mathrm{Mg}(0.28,0.38$ and $1 \% \mathrm{Mg})$, were solubilized for $10 \mathrm{~h}$ at $5400 \mathrm{C}$ and subjected to different temperatures and times of artificial aging. The results showed that the hardness rises with increasing aging temperature, but exhibits a sharp drop in samples exposed to higher temperatures (2150 C). Regarding aging time, increments were observed in the hardness values for the use of higher aging times. In order to identify microstructural changes associated with modifications in mechanical properties and to identify the mechanisms involved, analyzes were performed by optical microscopy, scanning and transmission electron microscopy. Significant changes in the microstructure and the hardening of the alloy matrix were found, as a function of increasing additions of magnesium. However, the microstructural phenomena associated with precipitation hardening 
were only detected by using transmission electron microscopy, which showed the presence of nano precipitates responsible for precipitation hardening as well as precipitates incoherent with the matrix, thus indicating the occurrence of overaging.

Keywords: heat treatments, aluminum alloys, precipitation hardening, transmission electron microscopy.

\section{INTRODUÇÃO}

A liga 356 (Al7Si0,3Mg) é uma das ligas de alumínio mais utilizadas na indústria aeroespacial e automobilística devido à sua baixa densidade em comparação com sua resistência mecânica [1]. HASKEL [2] mostrou que a liga na condição bruta de fundição apresenta uma microestrutura tipicamente constituída por dendritas de solução sólida rica em alumínio ( $\alpha \mathrm{Al})$ e partículas de silício (Si) formando um eutético irregular, com a possível presença de outras fases contendo alumínio (Al), silício ( $\mathrm{Si}$ ), ferro $(\mathrm{Fe})$ e magnésio $(\mathrm{Mg})$ na forma de precipitados na matriz de $\alpha \mathrm{Al}$ ou nas regiões interdendríticas. A maioria destes elementos de liga apresenta baixa tendência para formação dos nano precipitados endurecedores que aumentam a dureza e a resistência mecânica do material.

As ligas 356 também são ligas termicamente tratáveis, ou seja, podem ter sua resistência mecânica aumentada mediante tratamento térmico apropriado. Segundo LI et. al. [3], os mecanismos de endurecimento por precipitação no envelhecimento baseiam-se na formação de compostos intermetálicos durante a decomposição da solução sólida supersaturada metaestável, obtida por tratamento de solubilização. As propriedades mecânicas das ligas AlSi dependem da morfologia e distribuição das partículas de Si eutéticas. A fragilidade das fibras grosseiras de Si é a principal razão para baixa ductilidade e baixas resistências à ruptura e ao impacto. No entanto as partículas finas, dispersas e globulares de Si podem resultar em propriedades mecânicas excelentes. É possível obter melhorias significativas nas propriedades mecânicas das ligas, especialmente na ductilidade com o tratamento de solubilização e envelhecimento, que altera a morfologia e a distribuição dessas partículas $[2,4]$. Estudos anteriores mostram que ligas envelhecidas com alto teor de silício, acima de 5\%, possuem melhores propriedades mecânicas comparadas com ligas com baixo teor de silício [6].

A liga 356 possui diversos elementos que mediante tratamentos térmicos formam precipitados endurecedores como, por exemplo, o $\mathrm{Mg}_{2} \mathrm{Si}$, além das partículas de Si eutéticas. Nestas ligas, a partir da condição metaestável de solubilização é realizado o tratamento térmico de envelhecimento, que pode ser feito à temperatura ambiente (envelhecimento natural) ou então a temperaturas relativamente elevadas (envelhecimento artificial). Nas duas formas o princípio consiste na precipitação de uma fase a partir da solução sólida supersaturada. Esta precipitação envolve a formação de precipitados finamente dispersados que causam o endurecimento da liga. Durante os primeiros estágios do envelhecimento a principal mudança é a redistribuição dos átomos de soluto em solução sólida dentro da rede para formar "clusters" ou zonas de Guinier Preston que são zonas enriquecidas em soluto. O reaquecimento da liga solubilizada geralmente na faixa de 120 a $200^{\circ} \mathrm{C}$, em fornos com circulação forçada de ar, favorece a precipitação artificial submicroscópica da fase ou das fases intermediárias, com aumentos de dureza, resistência a tração e menor resistência a corrosão [7].

Durante os primeiros estágios de envelhecimento de uma liga Al-Si-Mg (356) $\left(155^{\circ} \mathrm{C} / 4 \mathrm{~h}\right)$, a solução sólida saturada, primeiro desenvolve conjuntos de soluto. Entretanto, a supersaturação de lacunas permite a difusão, então levando a formação das zonas de Guinier Preston - zonas GP. Um estado de sub-envelhecimento pode ser mantido. Este estado é conhecido por estar associado com a formação de uma microestrutura consistindo primariamente de zonas GP em forma de agulha ou arredondadas, forma de transição tipo agulhas $\beta$ " $\left(\mathrm{Mg}_{2} \mathrm{Si}\right)$ e bastões $\beta^{\prime}\left(\mathrm{Mg}_{2} \mathrm{Si}\right)$ [10]. Porém, quando a liga é tratada a temperaturas mais elevadas $\left(215^{\circ} \mathrm{C}\right)$ ocorre engrossamento e perda da coerência dos precipitados com a matriz, o que resulta em diminuição das propriedades mecânicas [6,7].

Em estudos realizados por RONSANI [7] foi constatado que as propriedades mecânicas variavam de acordo com o tratamento térmico realizado. As propriedades mecânicas em geral, aumentavam com o aumento da temperatura até a temperatura de $175^{\circ} \mathrm{C}$ a partir da qual houve uma queda das propriedades, esses eventos se devem a microestrutura formada em cada tratamento. Algumas condições se mostraram importantes para que a evolução destes acontecimentos fossem visualizados, essas condições foram escolhidas como base de estudos para este trabalho.

Segundo MISHRA et. al [5], durante a solubilização das ligas alumínio-silício contendo magnésio, a dissolução do magnésio nos compostos intermetálicos ocorre em maior quantidade que a dissolução dos outros elementos. Assim, no estado T6 a concentração de magnésio nas dendritas de alumínio é bem maior do que na condição bruta de fusão (BF), resultando no aumento na quantidade dos precipitados $\mathrm{Mg}_{2} \mathrm{Si}$ tipo ( $\left.\beta^{\prime}\right)$, que são os principais responsáveis pelo aumento da dureza da matriz da liga 356.

A identificação precisa dos precipitados $\mathrm{Mg}_{2} \mathrm{Si}$ é difícil uma vez que necessita a utilização de técnicas sofisticadas de microscopia eletrônica de transmissão (TEM) em função de suas dimensões nano métricas. 
Trabalhos recentes $[8,9]$ investigaram detalhadamente os efeitos dos parâmetros tempo, temperatura de tratamento térmico nas propriedades mecânicas da liga 356, ricas em magnésio. Dentro deste contexto, os principais objetivos deste trabalho foram: (a) realizar tratamentos térmicos de solubilização e envelhecimento na liga A356, utilizando parâmetros de tratamento T6, em especial a temperatura de envelhecimento, que resultaram nos maiores valores de resistência e dureza, bem como a condição de temperatura que resultou em que brusca nos valores de dureza; (b) analisar os resultados utilizando ensaios de microdureza; (c) identificar, usando TEM, as alterações microestruturais decorrentes do tratamento T6, em especial a formação dos precipitados responsáveis pelo endurecimento por precipitação e pelo superenvelhecimento.

\section{MATERIAIS E MÉTODOS}

Os experimentos foram realizados de acordo com a metodologia experimental apresentada de forma esquemática na figura 1. Incialmente foram realizadas as corridas experimentais, nas quais foram fundidas amostras em forma de moedas (diâmetro 49,7mm e espessura 6,14mm) usando fusão por indução em um forno da marca Inductotherm modelo VIP PT 10 - $30 \mathrm{Kw}$ e um cadinho de carboneto de silício com capacidade para fundir até 1,2 kg de alumínio, após a fusão e tratamentos de desgaseificação e escorificação o metal foi vazado em coquilha.

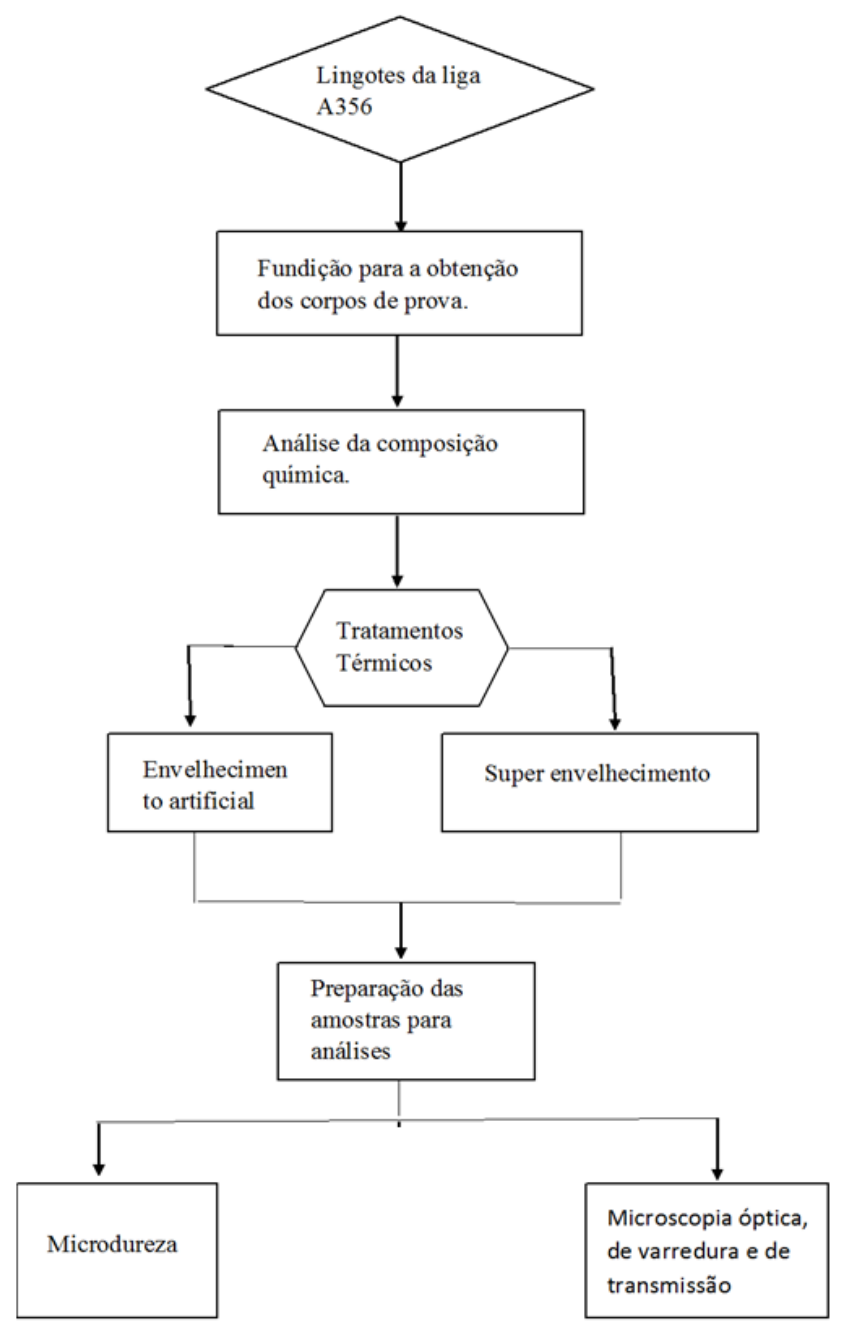

Figura 1: Diagrama representativo do método experimental utilizado na pesquisa.

A seguir as amostras fundidas foram submetidas a diferentes ciclos de tratamentos térmico, definidos a partir dos resultados obtidos em pesquisas anteriores [2,7-9], nas quais foram avaliadas as principais mudanças nas propriedades mecânicas das ligas 356 e A356 decorrentes de variações no tempo e na temperatura de solubilização e de envelhecimento Na sequência amostras das diferentes condições experimentais foram cortadas, lixadas, polidas e atacadas para análise em microscopia óptica e microscopia eletrônica de varredura, bem como para os ensaios de microdureza. Os ensaios de microdureza na matriz foram realizados usando um microdurômetro da marca Shimadzu, com carga de 25 g. Para as análises em microscopia ótica foi utilizado um mi- 
croscópio Olympus CX31, e para as análises de microscopia eletrônica de varredura um microscópio JEOL JSM-6701. As análises via microscopia eletrônica de transmissão (MET) foram realizadas no microscópio eletrônico de transmissão JEOL JEM 2100 operado com $100 \mathrm{KeV}$. Para as análises via MET as amostras foram submetidas a técnicas especiais de preparação, utilizando discos finos das ligas tratadas que foram lixados e polidos até a espessura de cerca de $100 \mu \mathrm{m}$, seguindo-se um polimento iônico para afinar ainda mais a amostra e, assim, permitir que o feixe de elétrons ultrapasse o material, através do equipamento PIPS (PrecisionIonPolishing System) da marca GATAN modelo 691.

Para avaliação do efeito do percentual de magnésio na liga 356 foram realizadas diferentes corridas experimentais variando-se a quantidade de magnésio adicionada. Amostras obtidas nestas corridas foram submetidas a análises químicas utilizando-se um espectrômetro de emissão óptica OES-5500II da Shimadzu. Os resultados destas análises são apresentados na tabela 1 e representam os valores obtidos a partir da média entre três queimas para cada amostra analisada.

Tabela 1: Composição química da liga 356.

\begin{tabular}{c|c|c|c|c|c|c|c}
\hline $\mathrm{Mg} \%$ & $\mathrm{Mn} \%$ & $\mathrm{Cu} \%$ & $\mathrm{Fe} \%$ & $\mathrm{Si} \%$ & $\mathrm{Ni} \%$ & $\mathrm{Zn} \%$ & $\mathrm{Al}$ \\
\hline 0,28 & 0,08 & 0,043 & 0,20 & 7,00 & 0,001 & 0,018 & Balanço \\
\hline 0,38 & 0,05 & 0,007 & 0,02 & 6,23 & 0,006 & 0,033 & Balanço \\
\hline 1,10 & 0,07 & 0,019 & 0,16 & 6,76 & $<0,001$ & $<0,012$ & Balanço \\
\hline
\end{tabular}

Os parâmetros dos tratamentos térmicos utilizados são apresentados na tabela 2, e foram escolhidos a partir dos resultados obtidos em trabalhos anteriores [8,9], nos quais foram investigados os efeitos de diferentes combinações de tempo e temperatura sobre a microestrutura e as propriedades mecânicas de ligas 356 e A356, nas condições solubilizada [8] onde foi constatado que os melhores resultados ocorreram para temperatura de $540^{\circ} \mathrm{C}$ e $10 \mathrm{~h}$ de aquecimento, e nas condições de envelhecimento com os maiores valores de resistência mecânica (155 ou $\left.175^{\circ} \mathrm{C}, 5 \mathrm{~h}\right)$, bem como nas condições em que ocorreu queda nas propriedades mecânicas $\left(215^{0} \mathrm{C}\right.$, 5 ou 8 h) $[7,9]$.

Tabela 2: Condições experimentais, destacando os ciclos de envelhecimento artificial utilizados.

\begin{tabular}{c|c|c|c|c}
\hline Amostra & Condição Experimental & $\begin{array}{c}\% \mathrm{Mg} \\
\text { (em peso) }\end{array}$ & Tempo (h) & Temperatura $\left({ }^{\circ} \mathrm{C}\right)$ \\
\hline 1 & Bruta de fundição (BF) & 0,28 & - & - \\
\hline 2 & Solubilizada & 0,28 & - & - \\
\hline 3 & Envelhecida & 0,28 & 5 & 155 \\
\hline 4 & Envelhecida & 0,28 & 5 & 175 \\
\hline 5 & Envelhecida & 0,28 & 5 & 215 \\
\hline 6 & Envelhecida & 0,28 & 8 & 155 \\
\hline 7 & Envelhecida & 0,28 & 2 & 215 \\
\hline 8 & Bruta de Fundição(BF) & 0,38 & - & - \\
\hline 9 & Solubilizada & 0,38 & - & - \\
\hline 10 & Envelhecida & 0,38 & 5 & 155 \\
\hline 11 & Envelhecida & 0,38 & 5 & 175 \\
\hline 12 & Envelhecida & 0,38 & 8 & 215 \\
\hline 13 & Envelhecida & 0,38 & 8 & - \\
\hline 14 & Bruta de Fundição(BF) & 1,00 & - & 155 \\
\hline 15 & Envelhecida & 1,00 & 5 & 215 \\
\hline 16 & Envelhecida & 1,00 & 5 & \\
\hline & & & & \\
\hline
\end{tabular}




\section{RESULTADOS E DISCUSSÃO}

\subsection{Microdureza}

Os resultados dos ensaios de microdureza realizados nas amostras obtidas nas diferentes condições de processamento são apresentados na figura 2.

As amostras submetidas a tratamentos térmicos apresentaram maiores valores de microdureza em comparação com as brutas de fundição (BF), para temperaturas de envelhecimento artificial de $155^{\circ} \mathrm{C}$ e $175^{\circ} \mathrm{C}$. Porém à temperatura de $215^{\circ} \mathrm{C}$, foram observados significativos decréscimos na microdureza para os diferentes teores de Mg investigados.

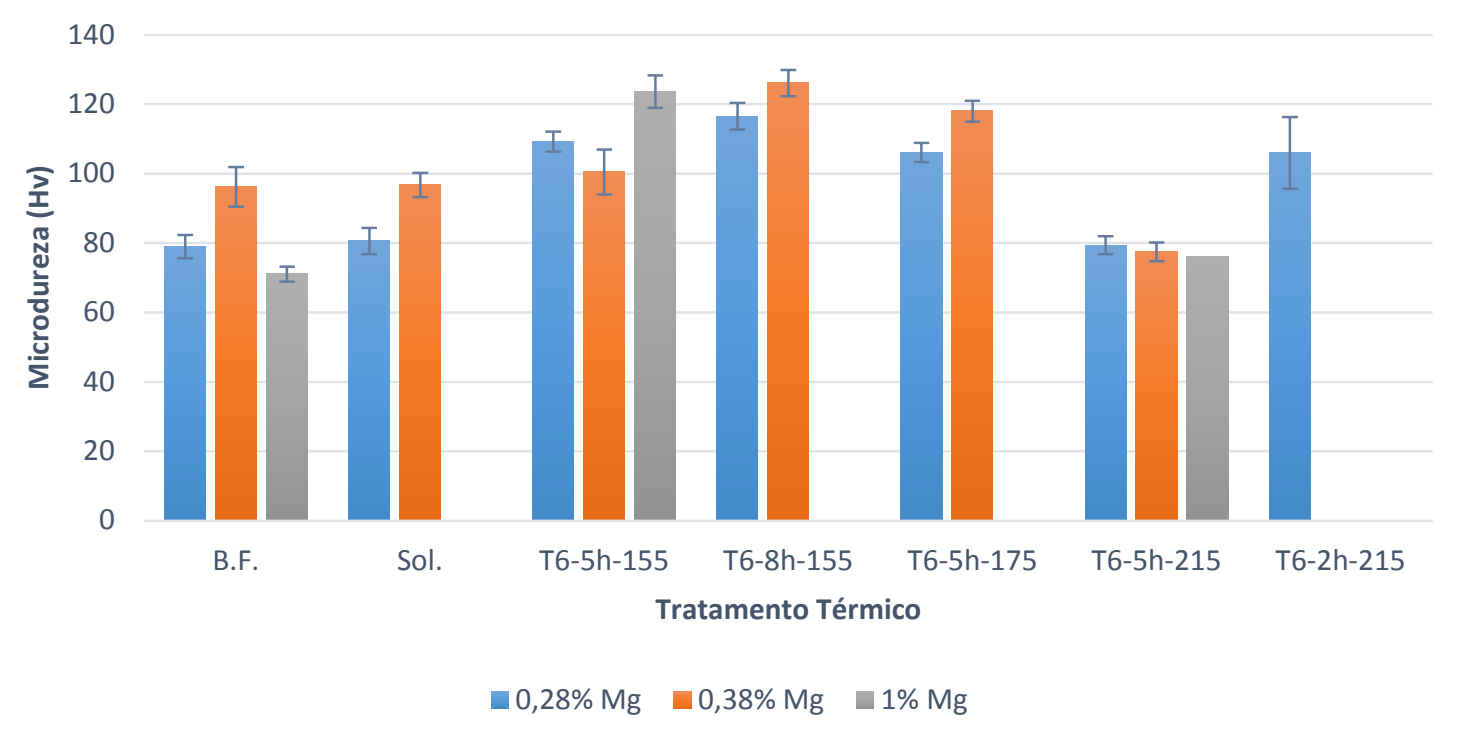

Figura 2: Valores de microdureza para as ligas com 0,28\%, 0,38\% Mg e 1\%Mg

Pode-se observar que as amostras BF apresentam os menores valores de microdureza, próximos a 78,96 $\mathrm{H}_{\mathrm{v}}$ para a liga com 0,28\% Mg, 96,2 $\mathrm{H}_{\mathrm{v}}$ para a liga com 0,38\% Mg e 71,08 $\mathrm{H}_{\mathrm{v}}$ para a liga com 1,0\% Mg. As amostras apenas solubilizadas apresentaram valores ligeiramente superiores comparados com as BF. A condição T6 envelhecida por $5 \mathrm{~h}$ à $155^{\circ} \mathrm{C}$, mostrou um significativo aumento na microdureza. Estes resultados ficaram muito próximos aos obtidos por RONSANI [7] que também constatou acréscimos na microdureza com o aumento da temperatura de envelhecimento, bem como uma redução considerável para o uso da temperatura de $215^{\circ} \mathrm{C}$. A figura 3 apresenta um comparativo entre os resultados deste trabalho e o de RONSANI [7], o que permite observar de forma mais clara a semelhança entre os valores de dureza obtidos para as diferentes condições de tratamento térmico e composição química investigadas. Esta comparação se torna importante, uma vez que o trabalho de RONSANI [7] envolveu um estudo mais abrangente dos efeitos dos parâmetros tempo e temperatura de envelhecimento sobre o comportamento mecânico da liga 356, com a realização de ensaios mecânicos de tração e microdureza, tendo sido observada uma excelente correlação entre as alterações na resistência mecânica e na microdureza. Estes resultados indicam que o uso da técnica de análise da microdureza se mostrou efetiva na caracterização dos efeitos destes tratamentos térmicos sobre as propriedades mecânicas da liga em estudo.

Os resultados obtidos neste trabalho também estão muito próximos aos obtidos por outros autores que investigaram o efeito combinado de tempo e temperatura de envelhecimento sobre a evolução das propriedades mecânicas de ligas da classe 356 [6,10].

Quanto ao percentual de $\mathrm{Mg}$, de maneira geral, quanto maior o teor de $\mathrm{Mg}$, maior o aumento da microdureza obtido com o tratamento térmico. Este fato sugere que o aumento de Mg em solução sólida supersaturada na liga possibilita formação de maiores quantidades dos nano precipitados endurecedores como o $\mathrm{Mg}_{2} \mathrm{Si}$. Amostras com 0,28\% Mg que foram envelhecidas durante duas horas a $215^{\circ} \mathrm{C}$ apresentaram maiores valores de microdureza mais rapidamente em comparação com temperaturas mais baixas, o que confirma a importância da temperatura e do tempo de envelhecimento na obtenção de propriedades mecânicas ótimas.

As amostras na condição T6 envelhecidas durante 5 horas à $215^{\circ} \mathrm{C}$ apresentaram um decréscimo acentuado na microdureza, sugerindo a ocorrência do fenômeno de superenvelhecimento, a partir destes resultados fo- 
ram selecionadas amostras tratadas termicamente das condições experimentais que apresentaram os maiores incrementos na microdureza e da condição experimental na qual foi observado um decréscimo acentuado na microdureza, para a realização das análises metalográficas.

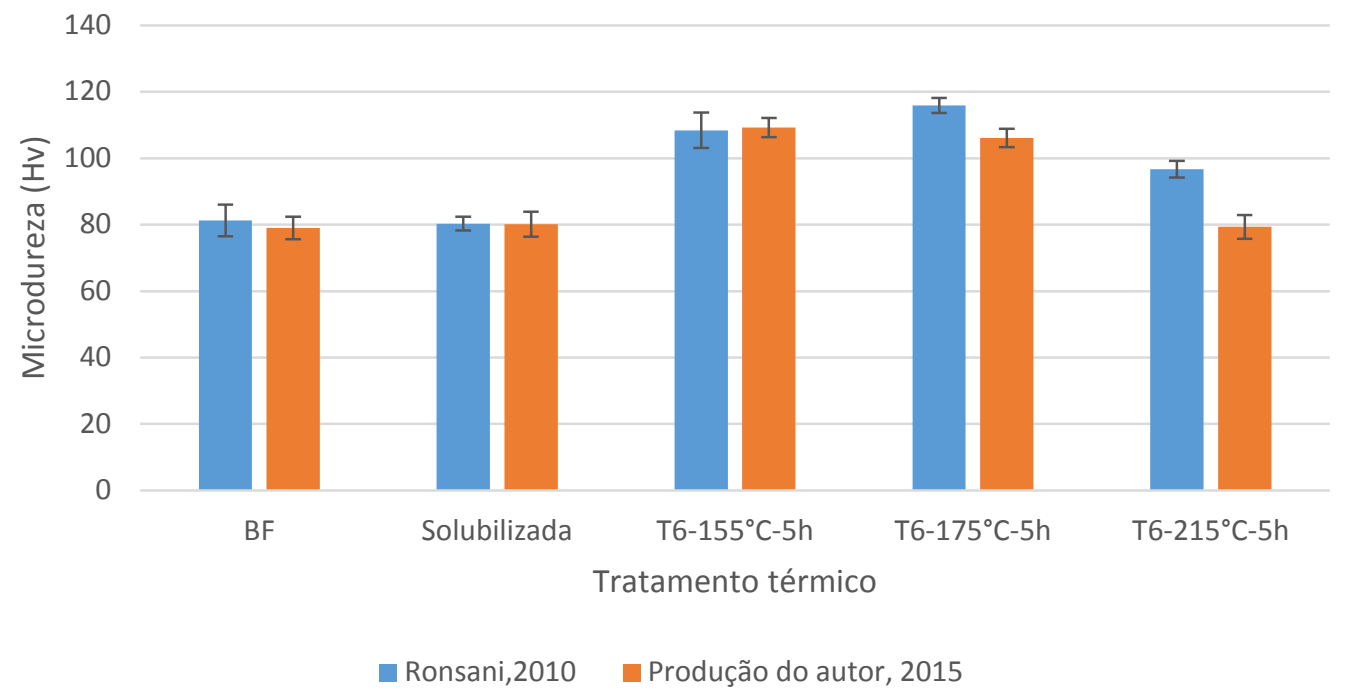

Figura 3: Comparativo dos resultados de microdureza deste trabalho com trabalho anterior.

\subsection{Microestrutura}

Após tratamento térmico foi possível notar uma alteração significativa na microestrutura da liga através da microscopia óptica. A figura 4 seguir apresenta uma amostra BF comparada com uma amostra tratada a $155^{\circ} \mathrm{C}$ durante 5 h (T6). Na amostra BF o silício eutético possui forma acicular e está envolto em dendritas de Ala (fig. 4.a), enquanto depois de tratada, a liga apresenta partículas de silício mais arredondadas e compactas como resultado do coalescimento durante o tratamento de solubilização (fig. 4.b), conforme observado anteriormente por Haskel et. al. [8].

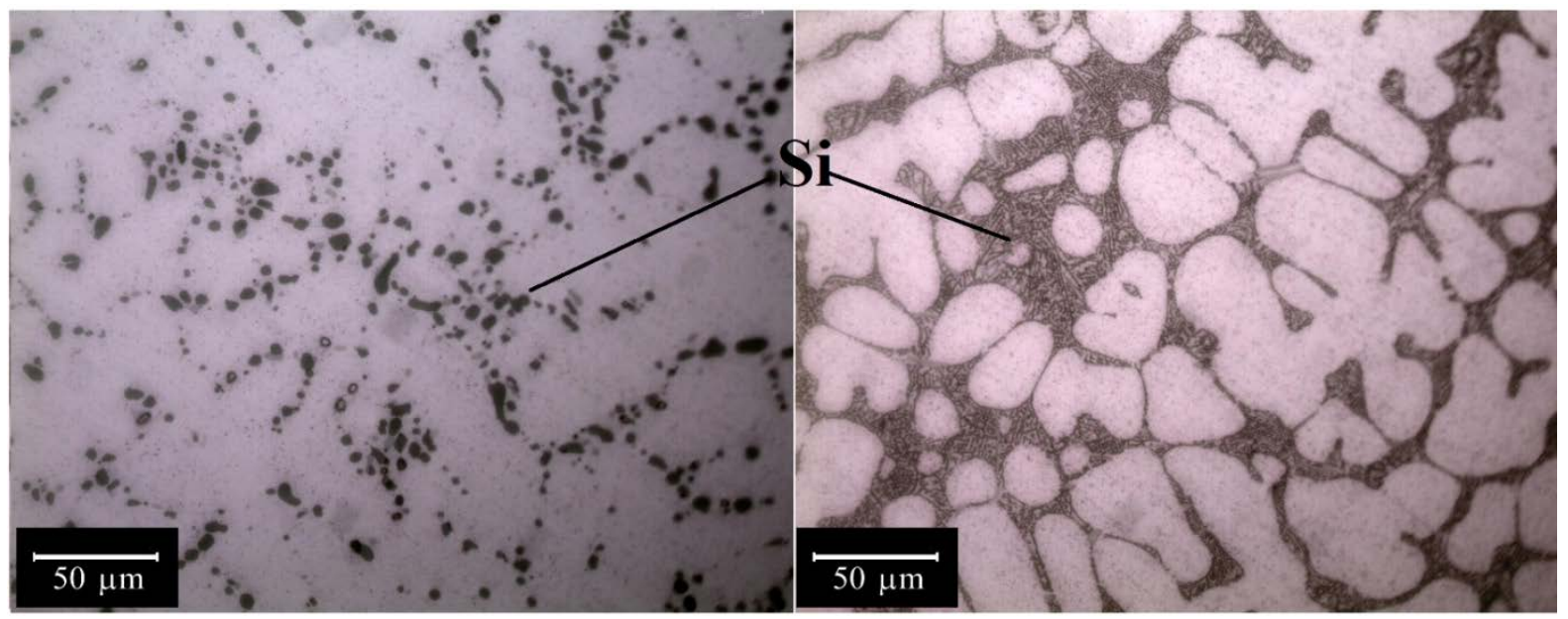

Figura 4: a) Microestrutura da liga 356 bruta de fundição (400x), b) T6 durante 5h a $155^{\circ} \mathrm{C}$.

As figuras 5.a e 5.b mostram que as partículas de silício (em cinza médio) modificadas através de tratamentos térmicos de solubilização e envelhecimento artificial, tornam-se mais esferoidais e equiaxiais, permitindo observar que o uso de maiores temperaturas de envelhecimento contribuiu para um maior coalescimento das mesmas. 


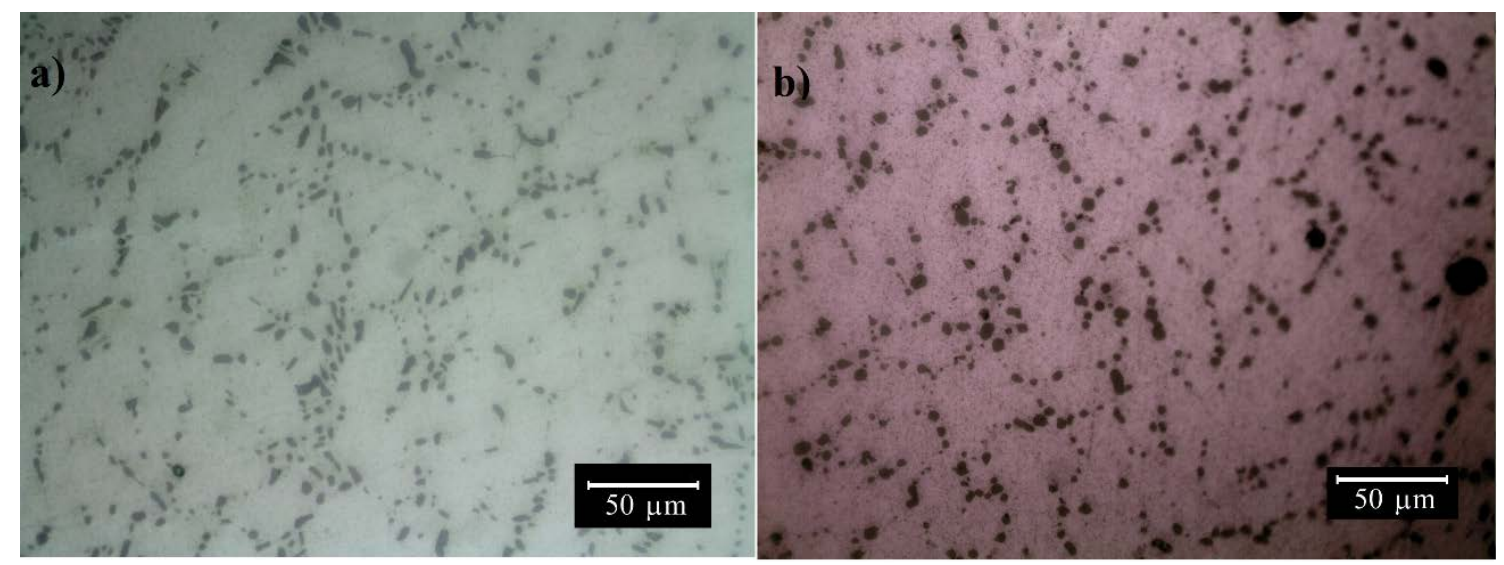

Figura 5: Micrografias de amostras submetidas ao tratamento térmico T6, a) envelhecida a $155^{\circ} \mathrm{C}$ por 5h, b) envelhecida a $215^{\circ}$ durante $5 \mathrm{~h}$.

Com o auxílio de microscopia eletrônica de varredura, foi possível visualizar mais claramente alguns precipitados, como é o caso do silício e do $\mathrm{Mg}_{2} \mathrm{Si}$ (figura 6.a), além de e outros intermetálicos como o acicular $\mathrm{\beta Al}_{5} \mathrm{FeSi}$ (figura 6.b). A figura 6.a, mostra uma amostra $\mathrm{BF}$ com precipitados de $\mathrm{Mg}_{2} \mathrm{Si}$ em uma forma mais acicular e agulhas de silício, todos estes precipitados foram identificados usando EDS.

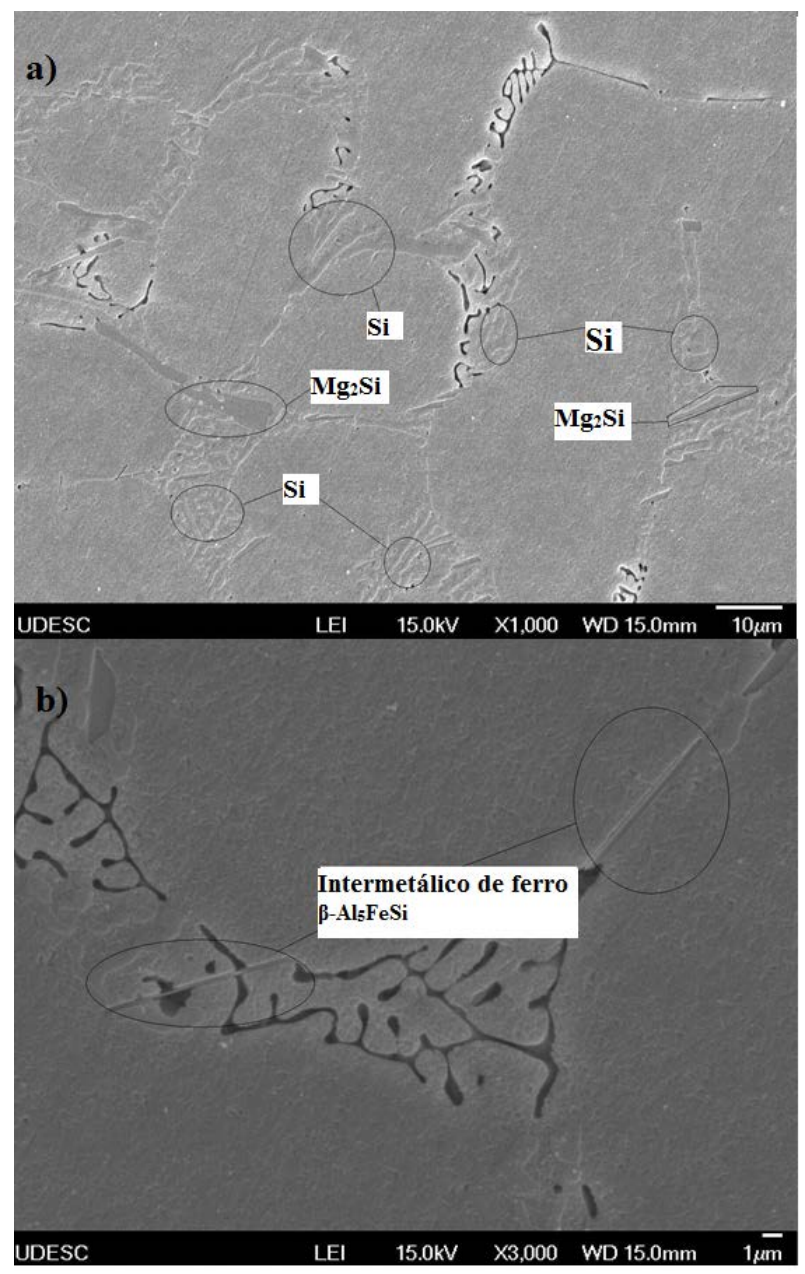

Figura 6: Microscopia eletrônica de varredura das amostras a) BF destacando os precipitados de $\mathrm{Mg}_{2} \mathrm{Si} 2$ e partículas de Si

b) uso de maior aumento para visualização dos intermetálicos tipo $\beta \mathrm{Al}_{5} \mathrm{FeSi}$.

As técnicas de microscopia ótica e eletrônica de varredura não permitem a visualização dos fenômenos microestruturais associados com a ocorrência do endurecimento por precipitação, tornando necessária a utilização da técnica de microscopia eletrônica de transmissão. MISHRA et. al [6] utilizou MET para estudar a 
liga 339 e detectou a presença de nove diferentes tipos precipitados que contribuíram para o aumento da resistência mecânica. Entre eles agulhas do precipitado $\mathrm{Mg}_{2} \mathrm{Si}$ com aproximadamente $10 \mathrm{~nm}$ de largura e $50 \mathrm{~nm}$ de comprimento, partículas de Si, entre outros.

As amostras tratadas com T6 foram analisadas usando MET com o objetivo de identificar os precipitados responsáveis pelo aumento na microdureza do material. As figura 7.a e 7.c mostram imagens de uma amostra com $1 \%$ de $\mathrm{Mg}$ tratada durante $5 \mathrm{~h} \mathrm{a} 155^{\circ} \mathrm{C}$, a figura 7.b apresenta imagem da mesma liga tratada por $5 \mathrm{~h}$ a $215^{\circ} \mathrm{C}$, neste caso, nota-se uma menor quantidade de pequenas agulhas do precipitado $\mathrm{Mg}_{2} \mathrm{Si}$ na liga tratada a $215^{\circ} \mathrm{C}$, além de precipitados mais grosseiros. A figura 7.d mostra grande quantidade de precipitados de precipitados de Si.
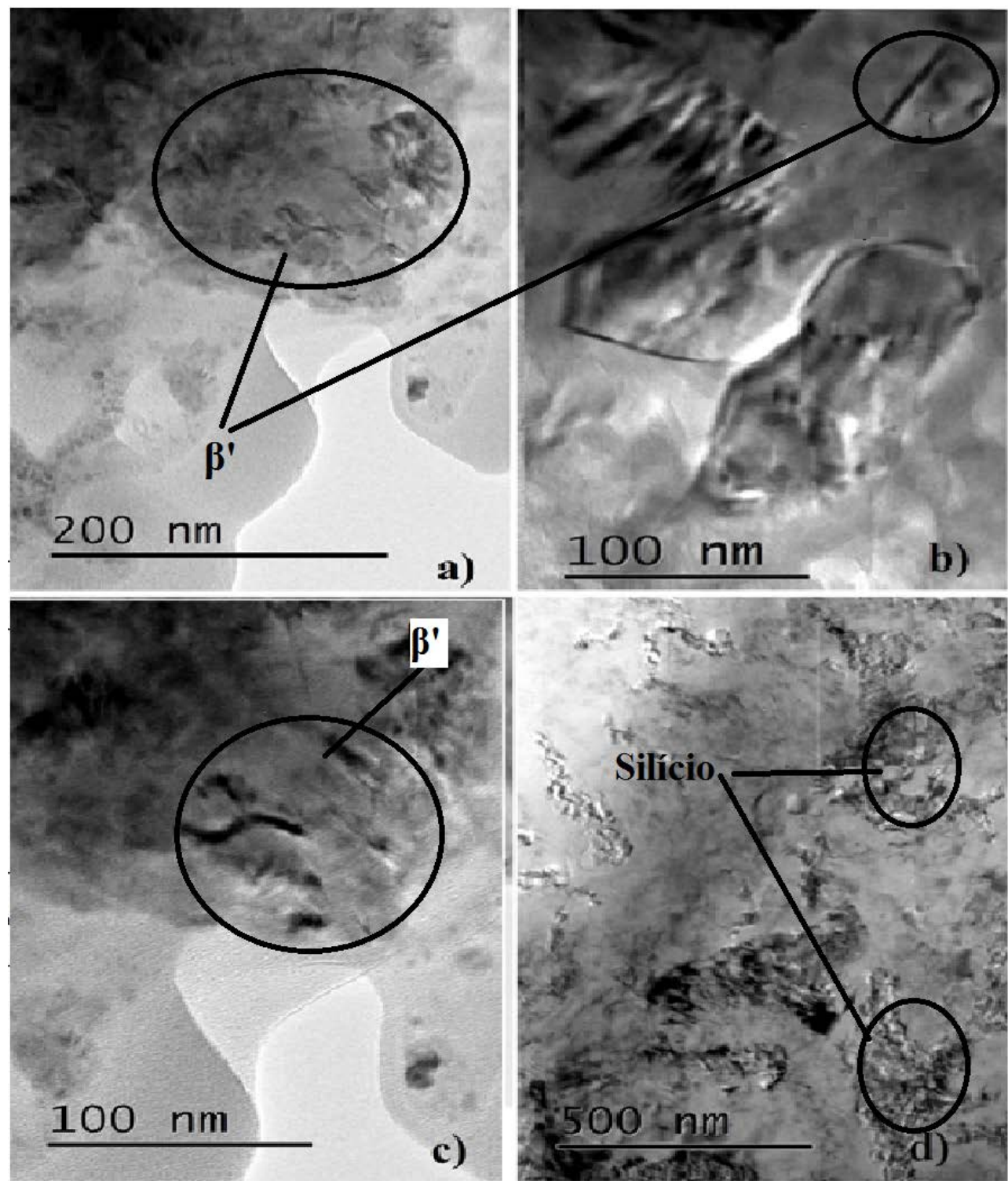

Figura 7: Imagens obtidas usando MET, a) e c) $\mathrm{T} 6$ 5h- $155^{\circ} \mathrm{C}$ b) $\mathrm{T} 65 \mathrm{~h}-215^{\circ}$ d) precipitados de $\mathrm{Si}$.

Na figura 8 é possível comparar as microestruturas de amostras tratadas a $155^{\circ} \mathrm{C}$ durante $5 \mathrm{~h}$ (a e b) e amostras tratadas a $215^{\circ} \mathrm{C}$ durante $5 \mathrm{~h}$. As amostras tratadas a $155^{\circ} \mathrm{C}$ apresentam precipitados menores ( $\beta^{\prime}$ ) em comparação com observados nas pelas amostras tratadas a $215^{\circ} \mathrm{C}$. As agulhas de $\mathrm{Mg}_{2} \mathrm{Si}\left(\beta^{\prime}\right)$ aparecem com cerca de $50 \mathrm{~nm}$ de comprimento nas figuras 8.a e 8.b, além da presença de outros pequenos precipitados que puderam ser identificados. Os precipitados mais grosseiros visualizados na figura 8.c são resultado do superenvelhecimento causado pelo uso de altas temperaturas de envelhecimento, sugerindo que estas temperaturas mais elevadas propiciam o crescimento dos precipitados de forma que os mesmos percam coerência com a matriz de Al $\alpha$ (formação de precipitados $\beta$ ) e, consequentemente, deixem de produzir barreiras para as discor- 
dâncias, tornando a liga menos resistente. Na figura 8.d pode-se observar a presença de precipitados mais grosseiros que foram identificados, usando EDS, como precipitados do tipo $\mathrm{Al}_{2} \mathrm{Cu}$.

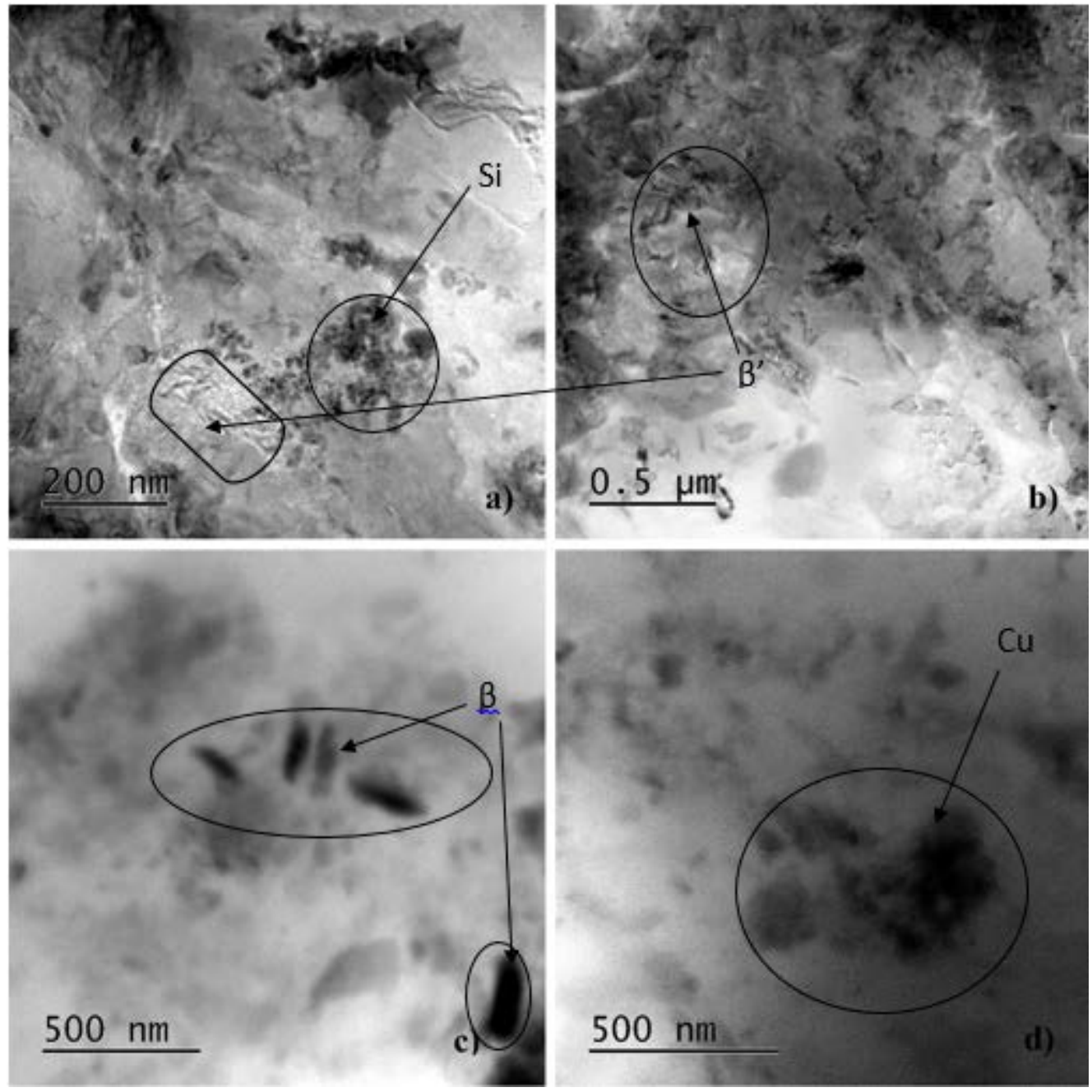

Figura 8: a) e b) MET de amostras tratadas durante $5 \mathrm{~h} \mathrm{a} 155^{\circ} \mathrm{C}$, c) e d) amostras tratadas $5 \mathrm{~h}$ a $215^{\circ} \mathrm{C}$.

Através da utilização de MET também foi possível observar o crescimento dos precipitados devido a ocorrência do superenvelhecimento. Para observar os precipitados tratados durante $5 \mathrm{~h}$ com temperatura de $155^{\circ} \mathrm{C}$ foram necessários aumentos muito maiores que variaram de 150.000 a $250.000 \mathrm{x}$, enquanto as amostras superenvelhecidas durante $5 \mathrm{~h}$ a $215^{\circ} \mathrm{C}$ exigiram aumentos que variaram de 40.000 a $150.000 x$.

\section{CONCLUSÕES}

Os resultados obtidos nesta pesquisa permitiram as seguintes conclusões:

1. Os parâmetros de tratamento térmico T6 investigados neste trabalho ocasionaram alterações significativas nos valores de microdureza da liga 356.

2. Na condição de envelhecimento que apresentou os melhores valores de microdureza $\left(155^{0} \mathrm{C}-5 \mathrm{~h}\right)$ a utilização de maior percentual de Mg se mostrou efetiva.

3. Os aumentos de tempo e temperatura no envelhecimento da liga resultaram em alterações diretamente proporcionais na microdureza da liga até atingir a condição de superenvelhecimento.

4. As partículas de silício se tornaram mais globulares devido ao tratamento T6, com possível contribuição para uma maior ductilidade da liga. 
5. Amostras com $0,28 \% \mathrm{Mg}$, envelhecidas durante duas horas a $215^{\circ} \mathrm{C}$ apresentaram aumento na microdureza mais rapidamente, em comparação com temperaturas mais baixas, o que confirma a importância da combinação da temperatura e do tempo de envelhecimento para a obtenção de propriedades mecânicas ótimas. Temperaturas mais elevadas requerem menores tempos de envelhecimento.

6. As amostras na condição T6 envelhecidas durante 5 horas a $215{ }^{\circ} \mathrm{C}$ sofreram redução acentuada na microdureza, sugerindo a ocorrência do fenômeno de superenvelhecimento.

7. A utilização de MET permitiu observar a presença dos nano precipitados responsáveis pelo endurecimento por precipitação e pelo superenvelhecimento.

\section{AGRADECIMENTOS}

À Universidade do Estado de Santa Catarina UDESC pelo apoio financeiro e bolsa de iniciação científica (Probic) e à Coordenação de Aperfeiçoamento de Pessoal de Nível Superior - CAPES pela bolsa de mestrado concedida.

\section{BIBLIOGRAFIA}

[1] ASM. Heat Treating.Metals Handbook, ASM International, v. 4, 1991.

[2] HASKEL, T., Efeito do Tratamento Térmico de Solubilização na Microestrutura e nas Propriedades Mecânicas da Liga de Alumínio A356, Dissertação de M.Sc., PGCEM/UDESC, Joinville, SC, Brasil, 2009.

[3] LI, R. X., LI, R. D., ZHAO, Y. H., et. al. “Age-hardening behavior of cast Al-Si base alloy”, Materials Letters, v.58, n.15, pp. 2096-2101,2004.

[4] HAGHSHENAS, M., ZAREI-HANZAKI, A., FATEMI-VARZANEH, S.M., "The effects of thermomechanical parameters on the microstructure of thixocast A356 aluminum alloy”, Materials Science and Engineering A, v.480, n.1-2, pp. 68-74, 2008.

[5] MISHRA, R. K., SACHDEV, A. K., BAXTER, W. J. “Strengthening Precipitates In Cast 339 Aluminum Alloy”, AFS Transactions, v. 21, pp.01-13, 2004.

[6] SAMUEL, E., SAMUEL, A. M., et. al., "Effect of $\mathrm{Zr}$ addition and aging treatment on the mechanical performance of Al-2\%Cu base alloys”, AFS Transactions, pp. 01-06, 2010.

[7] RONSANI, G. S. Tratamento de Envelhecimento Artificial das ligas 356 e A356: Efeitos da Adição de Magnésio, do Tempo e da Temperatura nas Propriedades Mecânicas, Dissertação de M.Sc, PGCEM/UDESC, Joinville, SC, Brasil, 2010.

[8] HASKEL, T., VERRAN, G. O. "Tratamento de solubilização da liga A356: efeitos do tempo e da temperatura”, In: 65h ABM International Congress Proceedings, 410-419, Rio de Janeiro, RJ, Brasil, 26-30 julho 2010.

[9] RONSANI, G. S., VERRAN, G. O., VILLELA, V. M. C. , et al. "Envelhecimento artificial das ligas 356 e A356: efeitos da composição química e dos parâmetros de processamento”, In: Anais do12 Seminário de Metais Não Ferrosos da ABM, 132-142, São Paulo, SP, Brasil, 30-31 de outubro 2011.

[10] TASH, M., SAMUEL, F.H., MUCCIARDI,F., et al., "Effect of metallurgical parameters on the hardness and microstructural characterization of as cast and heat treated 356 and 319 aluminum alloys”, Materials Science and Engineering A., v.443, pp.185-201, 2007. 